\title{
The Gluten Free Diet's Impact on Growth in Children with Celiac Disease in Two Different Countries
}

\author{
Naire Sansotta ${ }^{1}$, Stefano Guandalini ${ }^{2, *}{ }^{\mathbb{D}}$, Simone Romano ${ }^{3}$, Karine Amirikian ${ }^{2}$, \\ Marco Cipolli ${ }^{4}$, Gloria Tridello ${ }^{4}$, Silvia Barzaghi ${ }^{5}$ and Hilary Jericho ${ }^{2}$ \\ 1 Department of Pediatric Hepatology, Gastroenterology and Transplantation, Hospital Papa Giovanni XXIII, \\ 24127 Bergamo, Italy; nsansotta@asst-pg23.it \\ 2 Department of Pediatrics, Division of Gastroenterology, Hepatology, Nutrition, Celiac Disease Center, \\ University of Chicago Medicine, Comer Children's Hospital, Chicago, IL 60637, USA; \\ karine.amirikian@gmail.com (K.A.); hjericho@peds.bsd.uchicago.edu (H.J.) \\ 3 Department of Medicine, University of Verona, 37129 Verona, Italy; simone.romano@univr.it \\ 4 Cystic Fibrosis Center, Azienda Ospedaliera Universitaria Integrata, 37126 Verona, Italy; \\ marco.cipolli@aovr.veneto.it (M.C.); gloria.tridello@aovr.veneto.it (G.T.) \\ 5 Pediatric Department, University of Milano-Bicocca, Fondazione MBBM, San Gerardo Hospital, \\ 20900 Monza, Italy; silvia.barzaghi8@gmail.com \\ * Correspondence: sguandalini@peds.bsd.uchicago.edu
}

Received: 29 April 2020; Accepted: 22 May 2020; Published: 26 May 2020

\begin{abstract}
The effects of gluten free diet (GFD) on body mass index (BMI) and growth parameters in pediatric patients with celiac disease (CD) and their dependence on different socio-cultural environments are poorly known. We conducted an international retrospective study on celiac patients diagnosed at the University of Verona, Italy, and at the University of Chicago, Chicago, IL, USA, as underweight. A total of 140 celiac children and 140 controls (mean age 8.4 years) were enrolled in Chicago; 125 celiac children and 125 controls (mean age 7.3 years, NS) in Verona. At time of diagnosis, Italian celiac children had a weight slightly lower $(p=0.060)$ and a BMI z-score significantly $(p<0.001)$ lower than their American counterparts. On GFD, Italian celiac children showed an increased prevalence of both underweight (19\%) as well as overweight (9\%), while American children showed a decrease prevalence of overweight/obese. We concluded that while the GFD had a similar impact on growth of celiac children in both countries, the BMI z-score rose more in American than in Italian celiac children. Additionally, in Italy, there was an alarming increase in the proportion of celiac children becoming underweight. We speculate that lifestyle and cultural differences may explain the observed variations.
\end{abstract}

Keywords: celiac disease; gluten free diet; body mass index

\section{Introduction}

Celiac disease (CD), is a lifelong condition that affects the small intestine in genetically susceptible individuals [1]. In children, the symptoms attributable to the disease are highly variable and are influenced by age [2]. Growth failure in terms of length (or height) or weight may be the earliest sign of the disease reported in $14 \%$ of children at diagnosis [3,4]. However, between $11 \%$ and $13 \%$ of patients have been noted to be overweight or even obese at presentation $[5,6]$. Currently, the only effective treatment for CD is a strict, lifelong adherence to a GFD. This typically results in resolution of small intestinal inflammation and associated symptoms [7].

While a strict GFD can be nutritionally adequate [8], if not done properly, it can have the potential to lead to certain nutritional deficiencies [9-11] as well as to excess caloric intake and unintentional weight gain [12]. 
There is little data on BMI in pediatric CD patients following a GFD [13-15]. Valletta et al. found that the BMI z-score increased significantly, and the percentage of overweight subjects almost doubled in 149 CD children on the GFD in Italy [16]. Again, in another Italian study, Brambilla et al. showed that the percentage of overweight subjects increased slightly in 150 children with CD on a GFD [17], in agreement with Capriati et al. who found an increase of both overweight and obese patients after GFD in 445 biopsy-confirmed CD children [18]. On the other hand, in the United States, Reilly et al. demonstrated that the BMI of $75 \%$ of the patients with a high BMI at diagnosis decreased on a GFD in 142 CD children [13].

Considering the limited available literature in children, the present study has the potential of increasing our understanding on the prevalence of normal BMI and overweight among two different cohorts of children with $\mathrm{CD}$ and better characterizing the changes that occur in growth indices following long term treatment with GFD, as compared to healthy peers in a follow up period of 3 years.

\section{Materials and Methods}

We conducted a large international collaborative retrospective study to compare the impact of the gluten free diet in celiac pediatric populations of two different countries: The United States of America (USA) and Italy. We hypothesized that the greater availability of industrialized gluten free products in the US would lead to a higher increase of BMI in the American celiac children than in the Italian ones.

The study population included children with CD on the GFD who were enrolled between 2002 and 2016 and were followed for more than 6 months, as well as age and gender matched healthy controls.

Celiac disease cases. Before inclusion in the study, a diagnosis of $\mathrm{CD}$ was confirmed according to the current guidelines $[1,19]$. The inclusion criteria for our study were positive serology and Marsh 1-3 findings on biopsy, Tissue Transglutaminase IgA (TTG-IgA) more than 10 times the upper limit of normal with positive Endomysial antibody (EMA-IgA) with or without a biopsy, or positive serology and skin biopsy for dermatitis herpetiformis. In the case of IgA deficiency, Deamidated Gliadin Peptide (DGP) IgG was used. Exclusion criteria were underlying syndromes (Down, Turner, Ehlers-Danlos). Data regarding gender, age at the diagnosis, weight, height (before GFD and during follow up), mode of disease presentation, serological assays (TTG IgA, total IgA, EMA IgA and DGP IgA/IgG levels) were collected. Mode of presentation at the time of initial CD diagnosis was classified as gastrointestinal, extraintestinal or asymptomatic. Non-adherence to the GFD was assessed through patient self-reporting to their primary physicians and evaluation of celiac serologies. Participants were classified as "strictly adherent" if they reported strict adherence during the visits and had continued improvement of their serum TTG IgA and/or EMA antibodies. Patient reports to physicians were recorded into our celiac patient registry following their visits and analyzed retrospectively for this study. Of note, all dietitians' notes, whenever available, were reviewed to corroborate the assessment of dietetic adherence. There was no controlled system in place to further classify the extent of the patient's dietetic adherence.

Matched controls were recruited among children who did not have any siblings with $\mathrm{CD}$ who were seen for a well-child visit, or non-GI related complaint at the emergency room, or general pediatric clinic in Chicago, US, and Verona, Italy. These healthy children were matched for age, sex and ethnicity (white non-Hispanic).

The ethical committee of the University Hospital of Verona and the Institutional Review Board of the University of Chicago Department of Pediatrics have approved the project.

\section{Anthropometric Assessment}

Anthropometric measurements were taken according the international recommendations, using an electronic scale for weight and a stadiometer for height. Body mass index was calculated according to the weight $(\mathrm{kg}) /$ height $\left(\mathrm{m}^{2}\right)$. BMI was recorded upon GFD initiation in addition to at least 1 other time point: 6 months, 1 year, 2 years, 3 years and more than 4 years. 
The height, weight and BMI of celiac patients and healthy controls were converted to age-specific percentiles and z-score or standard deviation (SD) derived from growth charts published by the Center for Disease Control and Prevention (CDC) [20] for American children and by The Society for Pediatric Endocrinology and Diabetes (SIEDP) [21] for Italian children. For children younger than 2 years, weight-for height percentiles were used instead of BMI [22].

Subjects were grouped into 3 categories according to the presenting BMI percentile, as defined by the current guidelines [20]: underweight (SD or z-score $<-1.65$ or $<5$ th percentile for age), normal BMI (SD or $\mathrm{z}$-score from -1.65 to 1.02 or from 5 th to 85 th percentile for age) and overweight (z-score $>1.02$ or $>85$ th percentile for age).

Data were analyzed during the observational period and were expressed as change in height, weight and BMI z-score over time (time points: 6 months, 1 year, 2 years, 3 years and $>3$ years).

\section{Results}

We conducted a review of the charts available in the electronic databases of pediatric patients followed between 2002 and 2016 at the University of Chicago Celiac Disease Center (through REDCap software) and at the Verona Hospital (through Iside software). Two hundred and sixty-five celiac children (140 from Chicago) and 265 healthy children (140 from Chicago) were identified. Demographics, gender, median age at diagnosis, adherence to the GFD and duration of clinic follow up are summarized in Table 1. No statistically significant differences were found between the four groups.

Table 1. Features of the enrolled patients.

\begin{tabular}{ccccc}
\hline & \multicolumn{2}{c}{ Italy } & US \\
\hline & Celiac (125) & Controls (125) & Celiac (140) & Controls (140) \\
\hline Gender & $\mathbf{N ~ ( \% )}$ & $\mathbf{N ~ ( \% )}$ & $\mathbf{N ~ ( \% )}$ & N (\%) \\
Female & & & & \\
Male & $93(74.4)$ & $83(66.4)$ & $93(66.4)$ & $90(64.3)$ \\
Age at diagnosis/time 0 & $32(25.6)$ & $42(33.6)$ & $47(33.6)$ & $50(35.7)$ \\
0-5.9 yrs & & & & \\
6-11.9 yrs & $51(40.8)$ & $38(30.4)$ & $43(30.7)$ & $46(32.8)$ \\
$>12$ yr & $59(47.2)$ & $68(54.4)$ & $59(42.1)$ & $77(55.0)$ \\
Median age at diagnosis/time 0 & $15(12.0)$ & $19(15.2)$ & $38(27.2)$ & $17(12.2)$ \\
Duration of follow-up & 7.32 & 8.64 & 8.4 & 8.05 \\
Median (years) & & - & & 2.19 \\
Range & 4.07 & 2.89 & $0.51-8.77$ & $0.59-5.17$ \\
GFD adherence (strict) & $0.53-12.58$ & $0.52-6.75$ & $116(82.8)$ & - \\
\hline
\end{tabular}

The most common referral symptoms in both groups were abdominal pain, failure to thrive, short stature and decelerated growth.

\subsection{Growth Parameters at Diagnosis}

In the Italian group, $6 \%$ of patients had an abnormally high BMI and 85\% presented with a normal BMI at diagnosis. The remaining $9 \%$ were underweight at the time of diagnosis (Figure 1). 


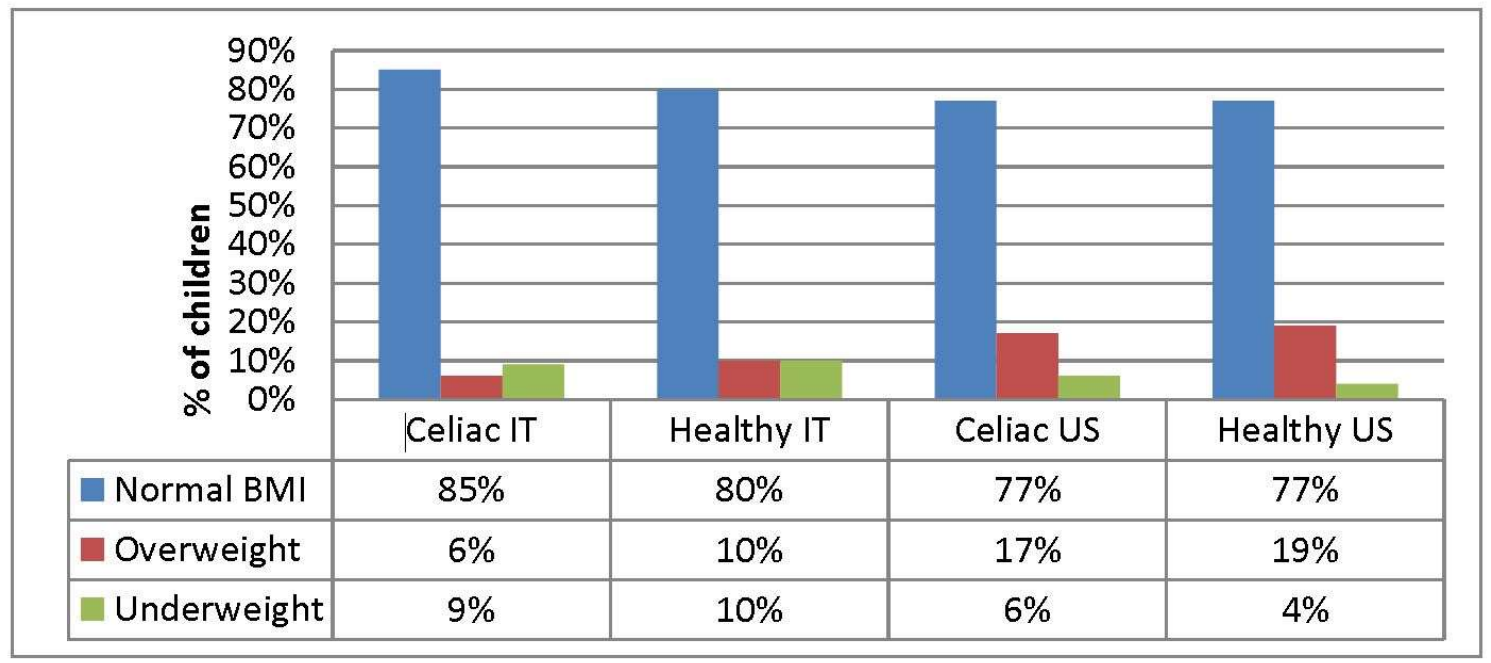

Figure 1. BMI at presentation.

Within the US Group, $17 \%$ of patients were overweight and obese, $77 \%$ had a normal BMI and $6 \%$ were underweight (Figure 1). At the time of diagnosis, Italian celiac children were noted to be thinner $(p=0.060)$ and with lower BMI scores $(p<0.001)$ as compared with US celiac children. There was no difference in height SD $(p=0.700)$. Height and weight $\mathrm{z}$-scores in Italian and American celiac children at the time of diagnosis were lower than their countrymen healthy peers, while no difference was found in BMI SDs (Table 2).

Table 2. Comparison between celiac and healthy children at time 0 .

\begin{tabular}{|c|c|c|c|c|}
\hline \multirow{2}{*}{$\begin{array}{l}\text { Country } \\
\text { Groups }\end{array}$} & \multicolumn{2}{|c|}{ Italy } & \multicolumn{2}{|c|}{ US } \\
\hline & $\begin{array}{c}\text { Celiac } \\
(\mathrm{N}=125)\end{array}$ & $\begin{array}{l}\text { Controls } \\
(\mathrm{N}=125)\end{array}$ & $\begin{array}{c}\text { Celiac } \\
(\mathrm{N}=140)\end{array}$ & $\begin{array}{l}\text { Controls } \\
(\mathrm{N}=140)\end{array}$ \\
\hline \multicolumn{5}{|l|}{ Height_SD } \\
\hline Median, range & $-0.5(-3.9-2.3)$ & $0.3(-2.4-2.8)$ & $-0.5(-4.4-2.3)$ & $0.1(-2.8-2.2)$ \\
\hline Mean (SD) & $-0.50(1.09)$ & $0.23(0.91)$ & $-0.59(1.26)$ & $0.09(0.97)$ \\
\hline$p$ value & \multicolumn{2}{|c|}{$p<0.0001^{*}$} & \multicolumn{2}{|c|}{$p<0.0001^{*}$} \\
\hline \multicolumn{5}{|l|}{ Weight_SD } \\
\hline Median, range & $-0.9(-4.1-2.5)$ & $-0.1(-3.3-1.8)$ & $-0.5(-5.2-2.6)$ & $0.1(-2.1-2.6)$ \\
\hline Mean (SD) & $-0.70(1.09)$ & $-0.12(0.91)$ & $-0.52(1.27)$ & $0.12(0.94)$ \\
\hline$p$ value & \multicolumn{2}{|c|}{$p<0.0001 *$} & \multicolumn{2}{|c|}{$P<0.0001 *$} \\
\hline \multicolumn{5}{|l|}{ BMI_SD } \\
\hline Median, range & $-0.6(-2.9-2.0)$ & $-0.4(-3.5-1.8)$ & $0.0(-6.3-2.4)$ & $0.1(-3.3-2.5)$ \\
\hline Mean (SD) & $-0.46(0.99)$ & $-0.37(1.03)$ & $-0.08(1.16)$ & $0.15(0.98)$ \\
\hline$p$ value & \multicolumn{2}{|c|}{$p=0.07$} & \multicolumn{2}{|c|}{$p=0.44$} \\
\hline
\end{tabular}

\subsection{Growth Parameters Over Time}

After initiation of the GFD, both Italian and American Celiac Children had an increase in height SD $(p<0.001)$ and weight SD $(p<0.010)$ while BMI z-score did not change $(p=0.133$ and $p=0.064$, respectively) (Table 3). 
Table 3. Changes of anthropometric parameters over time in celiac children.

\begin{tabular}{|c|c|c|c|c|}
\hline & \multicolumn{2}{|c|}{ Celiac IT } & \multicolumn{2}{|c|}{ Celiac US } \\
\hline & $\begin{array}{c}\text { Before GFD } \\
(\mathrm{N}=125)\end{array}$ & $\begin{array}{l}\text { After GFD } \\
(\mathbf{N}=125)\end{array}$ & $\begin{array}{c}\text { Before GFD } \\
(\mathrm{N}=140)\end{array}$ & $\begin{array}{l}\text { After GFD } \\
(\mathbf{N}=140)\end{array}$ \\
\hline \multicolumn{5}{|l|}{ Height_SD } \\
\hline Median, range & $-0.5(-3.9-2.3)$ & $-0.03(-2.4-3.3)$ & $-0.5(-4.4-2.3)$ & $-0.24(-2.4-3.6)$ \\
\hline Mean (SD) & $-0.50(1.09)$ & $-0.08(0.97)$ & $-0.59(1.26)$ & $-0.2(1.13)$ \\
\hline$p$ value & \multicolumn{2}{|c|}{$p<0.0001^{*}$} & \multicolumn{2}{|c|}{$p<0.0001^{*}$} \\
\hline \multicolumn{5}{|l|}{ Weight_SD } \\
\hline Median, range & $-0.9(-4.1-2.5)$ & $-0.6(-2.7-3.03)$ & $-0.5(-5.2-2.6)$ & $-0.04(-2.9-3.2)$ \\
\hline Mean (SD) & $-0.70(1.09)$ & $-0.49(1.07)$ & $-0.52(1.27)$ & $-0.09(1.05)$ \\
\hline$p$ value & \multicolumn{2}{|c|}{$p=0.0090 *$} & \multicolumn{2}{|c|}{$p<0.0001 *$} \\
\hline \multicolumn{5}{|l|}{ BMI_SD } \\
\hline Median, range & $-0.6(-2.9-2.0)$ & $-0.6(-3.14-2.15)$ & $0.0(-6.3-2.4)$ & $0.04(-2.16-2.68)$ \\
\hline Mean (SD) & $-0.46(0.99)$ & $-0.57(1.11)$ & $-0.08(1.16)$ & $0.07(0.92)$ \\
\hline$p$ value & \multicolumn{2}{|c|}{$p=0.1335$} & \multicolumn{2}{|c|}{$p=0.0646$} \\
\hline
\end{tabular}

No statistically significant difference was found in height z-score change between Italian and US celiac children $(p=0.700)$, while BMI z-score change was significant $(p=0.010)$, and weight $z$-score change was near significant $(p=0.050)$. The proportion of overweight children increased from 6 to $9 \%$ in Italy while the percentage of overweight and obese children decreased from $17 \%$ to $12 \%$ after initiation of the GFD in the US (Figure 2, Figure 3).

Of note, 24 of the 125 Italian CD children (19\%) were found to be underweight on GFD (BMI < 5th percentile): 13 of them presented failure to thrive at diagnosis, 10 had a weight in the 5-10th percentile and 1 had normal parameters at diagnosis (weight $>10$ th percentile). There was no statistically significant association between weight and age (median age 7.3 years, $p=0.1$ ); weight and gender $(p=0.1)$ and lastly, weight and duration of follow up $(p=0.2)$. The median time elapsed between initiation of the GFD and measurement of weight and height was 4.7 years for the Italian children vs 3.19 years for US children (NS). Twenty percent of underweight Italian celiac patients were poorly adherent to the GFD and/or had one or more comorbidities (depression, H. pylori infection). As compared to Italian celiac patients, only $4 \%$ of the US celiac were underweight on GFD and most of them presented with failure to thrive at the time of diagnosis. Again, there was no statistically significant association between weight and age (median age 8.4 years, $p=0.9$ ), age and either gender either duration of follow up ( $p=0.2, p=0.7)$. All of them were strictly adherent to the GFD, and no comorbidities were found. Overall, the proportion of overweight celiac children on the GFD was $9 \%$ in Italy vs. $12 \%$ in the US, while the proportion of underweight celiac children was $19 \%$ and $4 \%$, respectively.

No difference in height, weight, and BMI z-score was found over time in US healthy children $(p=0.9327, p=0.4328, p=0.7850$, respectively) as well as in Italian children $(p=0.4740, p=0.6992$, $p=0.9088$, respectively). There was also no significant difference in being overweight or obese between celiac patients and healthy peers in Italy or in the US. 


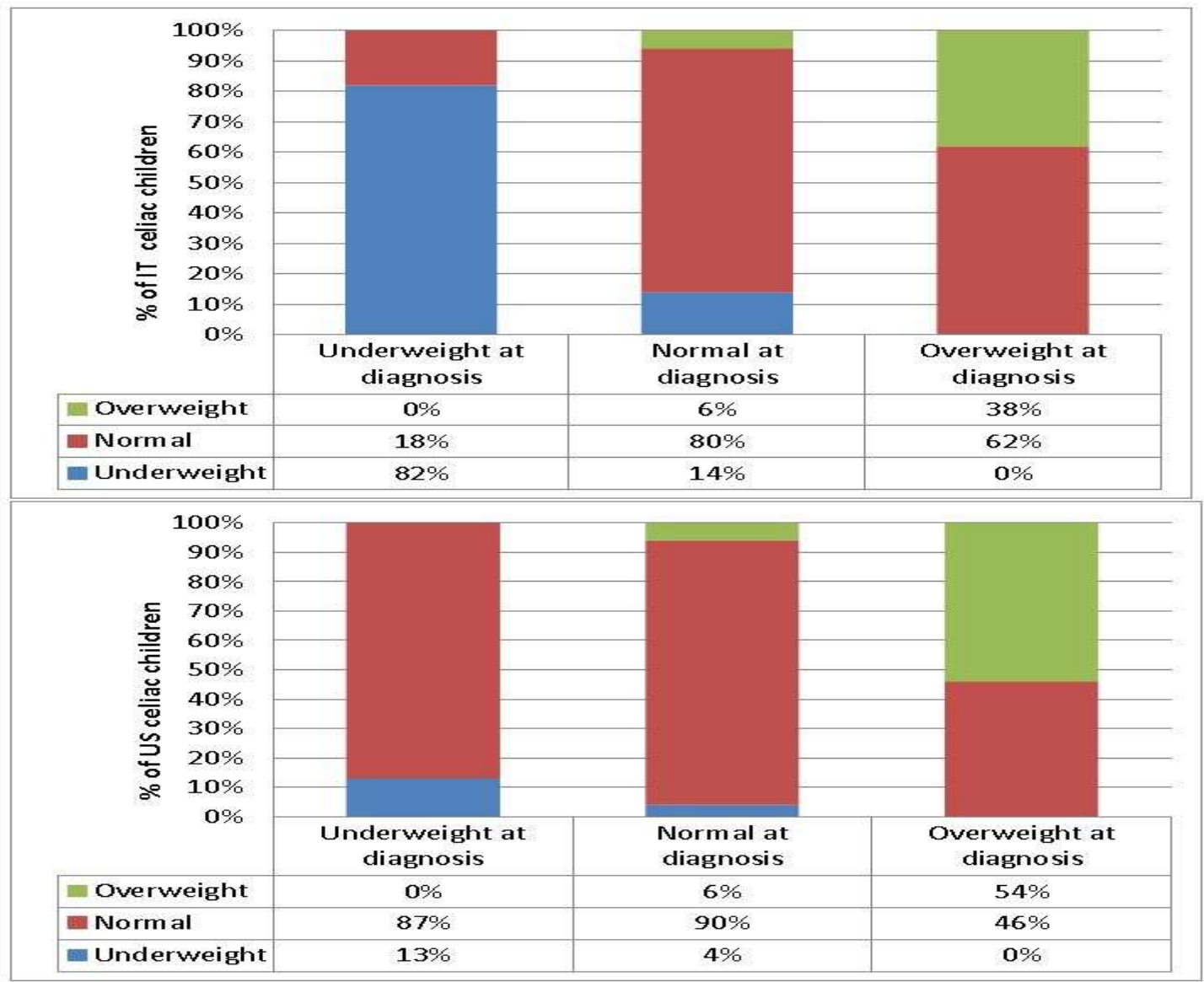

Figure 2. Gluten free diet (GFD) effect on BMI according to initial BMI in Italy and in the US.

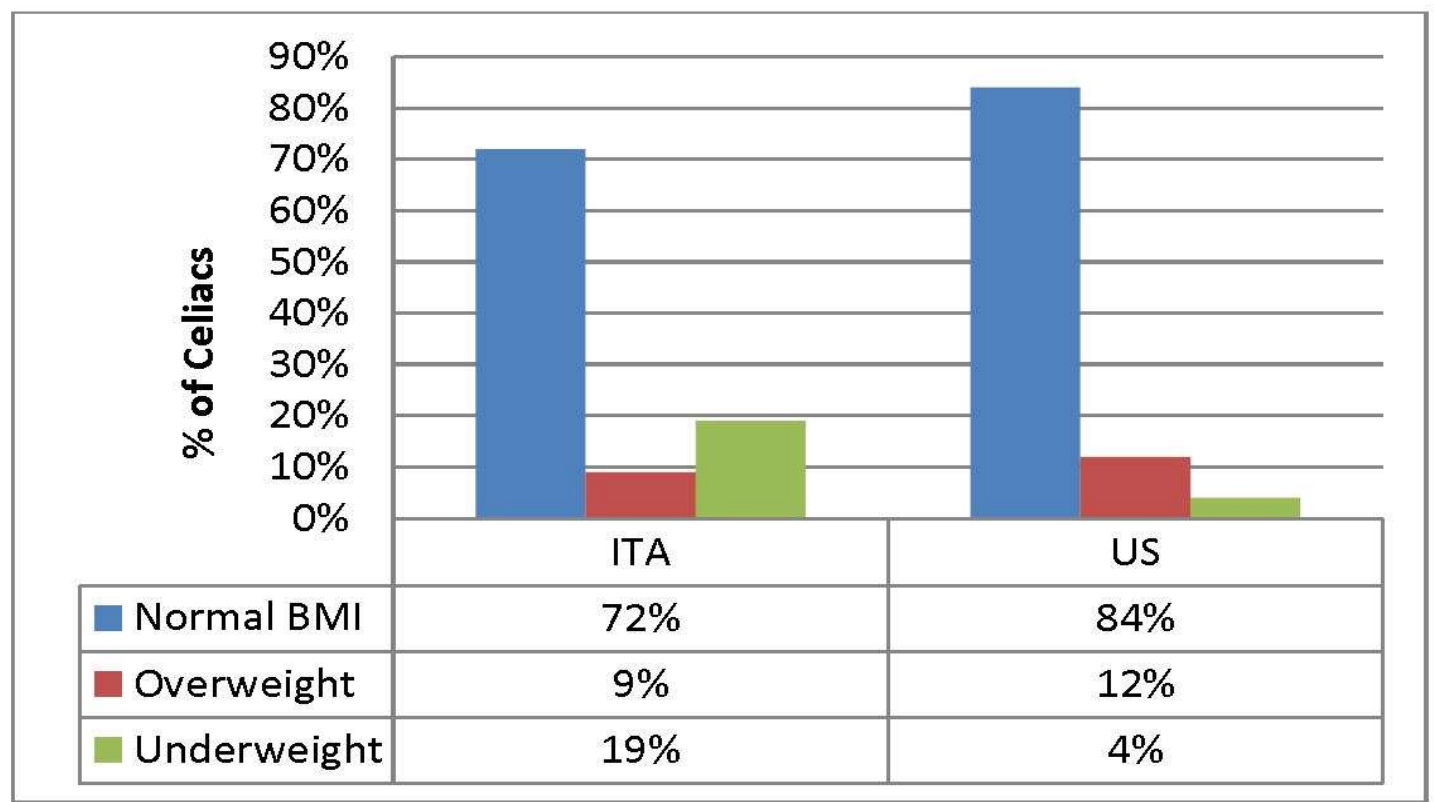

Figure 3. BMI at follow up in celiac groups.

\section{Discussion}

Here, we describe the varied impacts of the gluten free diet (GFD) in 2 groups of celiac disease children followed in two different countries: Italy and USA. To our knowledge, while studies have 
been published evaluating the change in body mass index (BMI) associated with the GFD in children with $C D$, no study has been published thus far evaluating all growth parameters on the GFD and between two separate countries. At diagnosis, no statistically significant differences in weight and height z-scores were found between Italian and US CD children, but BMI z-scores differed within the two countries. Eighty five percent of Italian CD children had a normal BMI at diagnosis as compared to $77 \%$ of American CD patients, in agreement with previous studies [23-25]. In the Italian CD group, $6 \%$ of patients were overweight/obese, and $9 \%$ were underweight at diagnosis, as compared to $17 \%$ and $6 \%$ in the US, respectively. Children with untreated CD were moderately shorter, weighed less and had a slightly lower (though not statistically significant) BMIs compared to their healthy peers in both countries. Although a GFD seems to improve the weight and body mass index of children with $\mathrm{CD}[26,27]$, there are few data regarding growth outcomes of children with CD with a low or elevated BMI. Recent studies in US adults with CD have shown a beneficial effect of the GFD regardless of BMI at diagnosis: obese patients lost weight, whereas underweight patients gained weight [28,29]; however, there is a trend towards the development of overweight/obesity in celiac patients who strictly comply with a GFD [12,30]. In our study, we did not find a significant change in BMI z-scores in pediatric CD groups following the GFD, though both CD populations had an increase in height SD and weight SD.

The proportion of overweight CD children on the GFD increased from $6 \%$ to $9 \%$ in Italy, similar to previous results [16], whereas in the US CD group, the percentage of overweight CD children decreased from $17 \%$ to $12 \%$ on the GFD in agreement with the literature [13]. BMI increases, whether desired or undesired after treatment of childhood CD, are probably multifactorial. Improved absorption likely plays a significant role, as suggested by substantial BMI increases among children with diarrhea in recent case reports [31,32]. The lack of palatability of some gluten free foods may induce a preference for the more hyperproteic and hyperlipidic foods leading to excessive weight gain [12,33]. Lifestyle factors, particularly dietary choices, which are different in the two countries, are likely to also play a role in the change of BMI.

On the other hand, few studies have been published rising the concern of children becoming underweight after GFD. Interestingly, we found that while only $4 \%$ of US celiacs were underweight on the GFD, $19 \%$ of CD children in Italy were underweight on the GFD. Of note, 50\% of Italian CD children who were underweight on the GFD had a previously normal BMI, and roughly $20 \%$ of them were found not to be adherent to the GFD and/or had other comorbidities, which were likely the main determining factors. In the US, underweight children on a GFD were previously underweight at the time of diagnosis with no other comorbidities. The reasons for these findings are unclear. We speculated that cultural difference plays a part in the availability of gluten free products and lifestyle factors. Factors likely to play a role are, for instance: home food availability, family eating habits (together as a family vs child eating apart from parents), choices of fast food over traditionally prepared foods, frequency of eating out vs home-made meals, child eating in school cafeteria vs their own home-prepared lunch, preferring a "Mediterranean diet" vs a more "Western diet", preferentially buying and eating manufactured vs natural Gluten-Free foods, etc.

We may further speculate that many celiac patients are inadequately educated and lean towards the availability of industry-generated gluten-free options, which result in unbalanced diets and food aversion, especially in those who presented failure to thrive at diagnosis. The evaluation of possible comorbidities and adherence to the GFD are important elements in the management of celiac children even though that explains less than $20 \%$ of underweight persistence in our population. Because of the nutritional risks associated with CD, a registered dietitian must be part of the health care team that monitors the patient's nutritional status and compliance on a regular basis in order to avoid malnourishment or worsening of previous status of overweight/obesity.

Furthermore, no difference in height, weight and BMI z-score was found over time in US healthy children or in Italian children. There was also no statistically significant difference in being overweight or obese between celiac patients and healthy peers in Italy or the US. 
Overall, this study has several strengths. To the best of our knowledge, it is the first international study where celiac children from two different countries were compared with their healthy peers. The weight and height measurements were also performed according to standard procedures (as opposed to self-reported), which makes our data very reliable. As is always the case in a retrospective study, there are implicit limitations. Although all patients underwent dietary review, and most of them had at least one consultation with an experienced dietician, detailed dietary inventories and standardized questionnaires to evaluate both the degree of strictness to the GFD and of gluten contamination were not available. We compared two different populations (Italy and USA), which are not completely comparable despite the use of adequate curves. Furthermore, our cohorts derived from two tertiary care referral centers, and as a result, our experience may differ from the types of cases and presentation of $\mathrm{CD}$ in other centers.

\section{Conclusions}

Pediatric literature on growth parameters of children with CD on the GFD compared with healthy controls has been limited up until now. Overall, the GFD seems to improve nutritional status in American children, decreasing the proportion of overweight and underweight celiacs. In Italy, there was a slight increase in the proportion of overweight and especially of underweight celiac children following the GFD, which may be related to differences between the two countries in availability of gluten free options and/or to culturally different approaches to the management of CD by the family of celiac children. Expert dietary counseling dedicated to managing the disease may be the most important factor in the management of CD. Future, prospective studies focusing on CD patients' choices of processed foods versus natural gluten free options in order to identify the factors responsible for these BMI alterations are needed.

Author Contributions: N.S.: methodology, investigation, drafted the manuscript. S.G.: conceptualization, supervision, reviewed and edited the manuscript. K.A.: data curation. S.R.: data curation. M.C.: methodology, reviewed the manuscript. G.T.: statistical analysis. S.B.: data curation. H.J.: methodology, supervision, reviewed the manuscript. All authors have read and agreed to the published version of the manuscript.

Funding: This research received no external funding.

Conflicts of Interest: The authors declare no conflict of interest.

\section{References}

1. Husby, S.; Koletzko, S.; Korponay-Szabó, I.; Kurppa, K.; Mearin, M.L.; Ribes-Koninckx, C.; Shamir, R.; Troncone, R.; Auricchio, R.; Castillejo, G.; et al. European Society Paediatric Gastroenterology, Hepatology and Nutrition Guidelines for Diagnosing Coeliac Disease. J. Pediatr. Gastroenterol. Nutr. 2020, 70, 141-156. [CrossRef] [PubMed]

2. Shamir, R.; Heyman, M.B.; Koning, F.; Wijimenga, C.; Gutierrez-Achury, J.; Catassi, C.; Gatti, S.; Fasano, A.; Discepolo, V.; Korponay-Szabo, I.R.; et al. Celiac Disease. J. Pediatr. Gastroenterol. Nutr. 2014, 59, S1. [CrossRef] [PubMed]

3. Van Dommelen, P.; Grote, F.K.; Oostdijk, W.; Keizer-Schrama, S.D.M.; Boersma, B.; Damen, G.M.; Csizmadia, C.G.; Verkerk, P.; Wit, J.; Van Buuren, S. Screening rules for growth to detect celiac disease: A case-control simulation study. BMC Pediatr. 2008, 8, 35. [CrossRef] [PubMed]

4. Tanpowpong, P.; Broder-Fingert, S.; Katz, A.J.; Camargo, C.A., Jr. Age-Related Patterns in Clinical Presentations and Gluten-Related Issues Among Children and Adolescents With Celiac Disease. Clin. Transl. Gastroenterol. 2012, 3, e9. [CrossRef] [PubMed]

5. Murray, J.A.; Van Dyke, C.; Plevak, M.F.; Dierkhising, R.A.; Zinsmeister, A.R.; Melton, L.J. Trends in the identification and clinical features of celiac disease in a North American community, 1950. Clin. Gastroenterol. Hepatol. 2003, 1, 19-27. [CrossRef]

6. Moscheo, C.; Vieni, G.; Pellegrino, S.; Pistulli, E.; Sansotta, N.; Zinnarello, C. The changing face of celiac disease: A girl with obesity and celiac disease. J. Paediatr. Child Health 2010, 46, 696. [CrossRef]

7. Di Sabatino, A.; Corazza, G.R. Coeliac disease. Lancet 2009, 373, 1480-1493. [CrossRef] 
8. Biagi, F.; Parnell, N.; Thomas, P.; Ellis, H.J.; Ciclitira, P. A new model for the pathogenesis of celiac disease. Gastroenterology 1999, 116, 1277-1278. [CrossRef]

9. Penagini, F.; DiLillo, D.; Meneghin, F.; Mameli, C.; Fabiano, V.; Zuccotti, G.V. Gluten-Free Diet in Children: An Approach to a Nutritionally Adequate and Balanced Diet. Nutrients 2013, 5, 4553-4565. [CrossRef]

10. Thompson, T.; Dennis, M.; Higgins, L.A.; Lee, A.R.; Sharrett, M.K. Gluten-free diet survey: Are Americans with coeliac disease consuming recommended amounts of fibre, iron, calcium and grain foods? J. Hum. Nutr. Diet. 2005, 18, 163-169. [CrossRef]

11. Hallert, C.; Grant, C.; Grehn, S.; Granno, C.; Hulten, S.; Midhagen, G.; Strom, M.; Svensson, H.; Valdimarsson, T. Evidence of poor vitamin status in coeliac patients on a gluten-free diet for 10 years. Aliment. Pharmacol. Ther. 2002, 16, 1333-1339. [CrossRef] [PubMed]

12. Dickey, W.; Kearney, N. Overweight in Celiac Disease: Prevalence, Clinical Characteristics, and Effect of a Gluten-Free Diet. Am. J. Gastroenterol. 2006, 101, 2356-2359. [CrossRef] [PubMed]

13. Reilly, N.R.; Aguilar, K.; Hassid, B.G.; Cheng, J.; DeFelice, A.R.; Kazlow, P.; Bhagat, G.; Green, P.H. Celiac Disease in Children with Normal Weight and Overweight: Clinical Features and Growth Outcomes Following a Gluten-Free Diet. J. Pediatr. Gastroenterol. Nutr. 2011, 53, 1. [CrossRef] [PubMed]

14. Van Der Pals, M.; Myléus, A.; Norström, F.; Hammarroth, S.; Högberg, L.; Rosén, A.; Ivarsson, A.; Carlsson, A. Body mass index is not a reliable tool in predicting celiac disease in children. BMC Pediatr. 2014, 14, 165. [CrossRef]

15. Ozkan, M.; Trandafir, L.; Mîndru, E.; Moraru, E. Variability of nutritional status and of the parameters of lipid metabolism in gluten-free diet. Revista Medico-Chirurgicala a Societatii de Medici si Naturalisti din Iasi 2012, 116, 103-107.

16. Valletta, E.; Fornaro, M.; Cipolli, M.; Conte, S.; Bissolo, F.; Danchielli, C. Celiac disease and obesity: Need for nutritional follow-up after diagnosis. Eur. J. Clin. Nutr. 2010, 64, 1371-1372. [CrossRef]

17. Brambilla, P.; Picca, M.; DiLillo, D.; Meneghin, F.; Cravidi, C.; Tischer, M.; Vivaldo, T.; Bedogni, G.; Zuccotti, G.V. Changes of body mass index in celiac children on a gluten-free diet. Nutr. Metab. Cardiovasc. Dis. 2013, 23, 177-182. [CrossRef]

18. Capriati, T.; Francavilla, R.; Ferretti, F.; Castellaneta, S.; Ancinelli, M.; Diamanti, A. The overweight: A rare presentation of celiac disease. Eur. J. Clin. Nutr. 2015, 70, 282-284. [CrossRef]

19. Husby, S.; Koletzko, S.; Korponay-Szabó, I.; Mearin, M.; Phillips, A.; Shamir, R.; Troncone, R.; Giersiepen, K.; Branski, D.; Catassi, C.; et al. European Society for Pediatric Gastroenterology, Hepatology, and Nutrition Guidelines for the Diagnosis of Coeliac Disease. J. Pediatr. Gastroenterol. Nutr. 2012, 54, 136-160. [CrossRef]

20. Flegal, K.M.; Cole, T.J. Construction of LMS parameters for the Centers for Disease Control and Prevention 2000 growth charts. Natl. Heal. Stat. Rep. 2013, 2013, 45069591.

21. Cacciari, E.; Milani, S.; Balsamo, A.; Spada, E.; Bona, G.; Cavallo, L.; Cerutti, F.; Gargantini, L.; Greggio, N.; Tonini, G.; et al. Italian cross-sectional growth charts for height, weight and BMI (2 to 20 yr). J. Endocrinol. Investig. 2006, 29, 581-593. [CrossRef] [PubMed]

22. De Onis, M.; Onyango, A.; Borghi, E.; Siyam, A.; Blössner, M.; Lutter, C. Worldwide implementation of the WHO Child Growth Standards. Public Health Nutr. 2012, 15, 1603-1610. [CrossRef]

23. McGowan, K.E.; Castiglione, D.A.; Butzner, J.D. The Changing Face of Childhood Celiac Disease in North America: Impact of Serological Testing. Pediatrics 2009, 124, 1572-1578. [CrossRef] [PubMed]

24. Garampazzi, A.; Rapa, A.; Mura, S.; Capelli, A.; Valori, A.; Boldorini, R.; Oderda, G. Clinical Pattern of Celiac Disease Is Still Changing. J. Pediatr. Gastroenterol. Nutr. 2007, 45, 611-614. [CrossRef] [PubMed]

25. Roma, E.; Panayiotou, J.; Karantana, H.; Constantinidou, C.; Krini, M.; Bamias, G.; Siakavellas, S.; Syriopoulou, V. Changing Pattern in the Clinical Presentation of Pediatric Celiac Disease: A 30-Year Study. Digestion 2009, 80, 185-191. [CrossRef]

26. Barera, G.; Mora, S.; Brambilla, P.; Ricotti, A.; Menni, L.; Beccio, S.; Bianchi, C. Body composition in children with celiac disease and the effects of a gluten-free diet: A prospective case-control study. Am. J. Clin. Nutr. 2000, 72, 71-75. [CrossRef]

27. Damen, G.M.; Boersma, B.; Wit, J.M.; Heymans, H.S.A. Catch-up Growth in 60 Children with Celiac Disease. J. Pediatr. Gastroenterol. Nutr. 1994, 19, 394-400. [CrossRef]

28. Cheng, J.; Brar, P.S.; Lee, A.R.; Green, P.H.R. Body Mass Index in Celiac Disease. J. Clin. Gastroenterol. 2010, 44, 267-271. [CrossRef] 
29. Murray, J.A.; Watson, T.; Clearman, B.; Mitros, F. Effect of a gluten-free diet on gastrointestinal symptoms in celiac disease. Am. J. Clin. Nutr. 2004, 79, 669-673. [CrossRef]

30. Anderson, C.D.; Turmelle, Y.P.; Darcy, M.; Shepherd, R.; Weymann, A.; Nadler, M.; Guelker, S.; Chapman, W.C.; Lowell, J.A. Biliary strictures in pediatric liver transplant recipients-Early diagnosis and treatment results in excellent graft outcomes. Pediatr. Transplant. 2010, 14, 358-363. [CrossRef]

31. Oso, O.; Fraser, N. A boy with coeliac disease and obesity. Acta Paediatr. 2006, 95, 618-619. [CrossRef] [PubMed]

32. Czaja-Bulsa, G.; Garanty-Bogacka, B.; Syrenicz, M.; Gebala, A. Obesity in an 18-Year-Old Boy With Untreated Celiac Disease. J. Pediatr. Gastroenterol. Nutr. 2001, 32, 226. [CrossRef] [PubMed]

33. Ferrara, P.; Cicala, M.; Tiberi, E.; Spadaccio, C.; Marcella, L.; Gatto, A.; Calzolari, P.; Castellucci, G. High fat consumption in children with celiac disease. Acta Gastro-Enterol. Belg. 2009, 72, 296-300.

(C) 2020 by the authors. Licensee MDPI, Basel, Switzerland. This article is an open access article distributed under the terms and conditions of the Creative Commons Attribution (CC BY) license (http://creativecommons.org/licenses/by/4.0/). 